\title{
Elderly Mortality from Cerebrovascular Disease in Alagoas, 2000-2016: Spatial- Temporal Analysis
}

\author{
Luiz Carlos Francelino Silva Junior, ${ }^{\circledR}$ Euclides José Oliveira Da Cunha, ${ }^{\circledR}$ Carlos Dornels Freire de Souza, ${ }^{\circledR}$ Alysson \\ Wagner Fernandes Duarte ${ }^{\circledR}$ \\ Universidade Federal de Alagoas - Campus Arapiraca, AL - Brazil
}

\section{Abstract}

Background: Cerebrovascular diseases (CVDs) are the second leading cause of death in Brazil.

Objective: This study aimed to describe the epidemiological profile and to analyze the spatiotemporal dynamics of mortality from cerebrovascular disease in the elderly in Alagoas from 2000-2016.

Methods: This is a multilevel ecological study of all deaths from CVD in individuals aged 60 years or older. Data were collected from the Mortality Information System. The variables were submitted to descriptive analysis, trend analysis by Joinpoint Regression method and spatial analysis with Global Moran's and local statistics; 95\% confidence interval and significance of $5 \%$ were considered in the analysis.

Results: There were 21,440 deaths in the study period, $50.4 \%(n=10,797)$ male, $40.5 \%(n=8,670)$ aged $\geq 80$ years, $44.5 \%$ $(n=9,465)$ of "brown" race, $30.1 \%(n=6,448)$ married and $36.5 \%(n=7,828)$ with less than four years of schooling. Female and male mortality rates were $460.24 / 100,000$ and $602.23 / 100,000$, respectively. An annual decreasing trend of $-1.4 \%(p<0.001)$ in overall and male mortality was observed from 2007 on. The highest mortality rates were concentrated in the eastern region of Alagoas (Moran's $I=0.766288$; $p=0.01$ ). Twenty-two municipalities were in quadrant Q1 of Moran's scattering diagram and considered priorities.

Conclusion: Death from CVD in Alagoas occurred equally in men and women in the study period, mostly in individuals of mixed race, married, and with low education attainment. The highest rates were observed in the eastern region of the state. The results highlight the need for public policies aimed at healthy aging in the state. (Int J Cardiovasc Sci. 2021; 34(2):159-167)

Keywords: Cerebrovascular Disorders; Cardiovascular Diseases; Respiratory Tract Diseases; Neoplasms; Epidemiology; Diabetes Mellitus; Mortality; Ecological Studies; Ethnic Inequality; Social Class.

\section{Introduction}

The accelerated aging of the Brazilian population has led to an increase in the rates of chronic non-communicable diseases (CNCDs), composed of cardiovascular diseases, chronic respiratory disease, diabetes mellitus and cancer. Among the cardiovascular diseases, ischemic heart disease (IHD) and cerebrovascular diseases (CVDs) are the two main causes of premature death in the world. ${ }^{1}$

CVDs are pathological conditions in which an area of the brain is transiently or permanently affected by ischemia or bleeding. ${ }^{2}$ The World Health Organization (WHO) estimates that in 2016, stroke and IHD were responsible for 15.2 million deaths worldwide. ${ }^{1}$

In Brazil, CVDs occupy the second position in number of deaths, just behind IHDs, ${ }^{3}$ moving from the eighth to the fourth position in the ranking of morbidities related to years of life lost (YLL) from 1990 to 2016. This expansion of CVD can be related to changes in lifestyle linked to urbanization and globalization processes, since the 1960s. ${ }^{4}$

Brazil is a country of continental dimensions, divided into regions with their own socioeconomic characteristics 
and epidemiological transition. ${ }^{3}$ The increase pattern of CVDs was first evidenced in the states of the south and southeast Brazil and later in the states of the north and northeast regions of the country. Therefore, efforts to prevent cerebrovascular events have become earlier in the states of the south and southeast regions and only more recently in the northern and northeastern regions of Brazil. 4

Given the above, this study aimed to describe the epidemiological characteristics and analyze the spatiotemporal dynamics of CVD mortality in the elderly population of the state of Alagoas, Brazil, from 2000 to 2016.

\section{Methods}

\section{Study Design, Population and Period}

This was a multilevel ecological study of all deaths from CVDs in residents aged 60 years or older in all cities of the state of Alagoas, Brazil, from 2000 to 2016.

\section{Study Location}

The study was carried out in Alagoas, the second smallest state on the northeast region of Brazil. The estimated population of Alagoas is 3.3 million (2018 census data), distributed into 102 municipalities. ${ }^{5}$ In the social context, the state has the lowest Human Development Index in Brazil (HDI 0.631) and 96.1\% of the municipalities have high or very high social vulnerability (6.7). In addition, $8.9 \%$ of the population is elderly, with an aging rate of $30.4 \%{ }^{6}$

\section{Study Variables}

In this study, the following sociodemographic variables were analyzed: sex (male and female), age group (60-69, 70-79, > 80 above, and unknown), marital status (single, married, widowed, separated, others, or unknown ), schooling (none, 1-3 years, 4-7 years, 8-11 years, > 12 years, or unknown) and color/race (white, black, yellow, mixed race, indigenous, or unknown). The mortality rates were analyzed according to the International Classification of Diseases (ICD-10), categories I60 to I69: I60 - Subarachnoid hemorrhage, I61 - Intracerebral hemorrhage, I62 - Other non-traumatic intracranial hemorrhages, I63- Cerebral infarction, I64 - Stroke not specified as hemorrhagic or ischemic, I65 - Occlusion / stenosis of pre-cerebral arteries that do not result in cerebral infarction, I66 - Occlusion / stenosis of cerebral arteries that do not result in cerebral infarction, I67 - Other cerebrovascular disorders, I68 - Cerebrovascular disorders classified in elsewhere diseases and I69 - Sequelae of cerebrovascular diseases.

\section{Data Source}

Mortality data were collected from the Mortality Information System (Ministry of Health).7 Mortality rates were calculated using the following equations:

a) Annual mortality rate: (number of deaths from CVDs in individuals aged 60 or over in the city and year / total of individuals aged 60 or over living in the city and year) x 100,000;

b) Average mortality rate (2000-2016): (average number of deaths from CVDs in individuals aged 60 or over in the city / total of individuals aged 60 or over living in the city in the middle of the period) $x 100,000$. Data were collected from the Brazilian Institute of Geography and Statistics.

\section{Statistical Analysis}

Data analysis was performed in three stages. The first stage consisted of sociodemographic description of the studied population (relative and absolute frequencies). The second stage was characterized by the analysis of mortality trends by identification of inflection points of the regression model (Joinpoint Regression Model). This model analyzes whether a line with multiple segments is more adequate to explain the time course of a data set compared with a straight line or a line with fewer segments. ${ }^{8}$ The model allows the calculation of the annual percentage change (APC) and the trend over the interval (AAPC, Average Annual Percent Change), as well as the classification of the trend as increasing, decreasing or stationary. ${ }^{8}$

The third stage was based on spatial modeling and identification of areas with the highest risk of deaths of elderly people due to CVD. Initially, municipal rates were subjected to smoothing by the local empirical Bayesian model to reduce the random fluctuation caused by rare events, small populations and underreporting of events. ${ }^{9,10}$ Soon after, global Moran's I was used to identify the global spatial dependence (spatial autocorrelation). The overall Moran's index varies between -1 and +1 , and the closer to 1 , the greater the spatial dependence of mortality from CVD in the elderly. Once the global 
autocorrelation was recognized, Moran's local statistics (LISA, Local Index of Spatial Association) was used to detect the areas with the highest risk of occurrence of the event. Using LISA, the municipalities were positioned in the quadrants of the Moran scattering diagram: Q1 - high / high (positive values and negative average values) and Q4 - low / high (negative values and positive average values). The municipalities located in the Q1 quadrant were considered priority. ${ }^{9,10}$ Then, thematic maps were made to present the results. The $95 \%$ confidence interval (95\% CI) and significance level of 5\% were considered in the statistical analysis.

The statistical analysis were made using the Joinpoint regression program version 4.5.0.1 (National Cancer Institute, Bethesda, MD, USA), Terra View (Version 4.2.2, Brazilian Space Research Institute - INPE, São José dos Campos, SP, Brazil) and QGIS (version 2.14.11, Open Source Geospatial Foundation- OSGeo, Beaverton, OR, USA).

\section{Ethical Aspects}

Since the study was based on analysis of secondary public data set and did not require identification of the individuals (which was also impossible), so ethics approval for the study was waived .

\section{Results}

In the period from 2000 to 2016, 21,440 deaths of elderly people due to CVD were recorded in Alagoas, with a slight predominance of men $(50.4 \%$; $=10,797)$. A total of $n=8,670(40.4 \%)$ of the individuals were aged 80 years or over, $44.2 \%(n=9,465)$ were brown color/race and $40.8 \%(n=4,407)$ were married. Considering educational attainment, $36.5 \%(n=7,828)$ of the population had less than 4 years of study. There was also a high proportion of "unknown" fields in the variables color/race $(31.3 \%$, $\mathrm{n}=6,708)$, marital status $(31.0 \%, \mathrm{n}=6,713)$ and education (54.7\%, n=11,719) (Table 1).

The average mortality rate was 523.6/100,000 considering both sexes, 602.2/100,000 for men and $460.2 / 100,000$ for women. In the temporal modeling, there was a trend of growth in the general (APC 3.9\%; $\mathrm{p}<0.001$ ), male (APC 4.1\%; p<0.001) and female (APC 3.6\%; $<<0.001$ ) rates between 2000 and 2007. In the following period (2007-2016), the trend was decreasing in general rate (APC $-1.4 \%$; $<<0.001$ ) and rate in male patients (APC $-1.4 \%$; $<0.001)$. Considering the total period, a stationary pattern was observed in the three rates (Figure 1).
Based on the ICD-10 categories, "unspecified stroke" was the most prevalent cause of deaths 364.17/100,000 (ICD I64), followed by "sequelae of cerebrovascular diseases" 73.69/100,000 (ICD I69). "Subarachnoid hemorrhage" (ICD I60) was the only category with predominance of female sex $(4.12 / 100,000$ in women and 2.39/100,000 in men). There were no deaths from "occlusion / stenosis of pre-cerebral arteries that do not result in cerebral infarction" (ICD I65), "occlusion / stenosis of cerebral arteries that do not result in cerebral infarction" (ICD I66) or "cerebrovascular disorders classified in elsewhere diseases"(ICD I68) reported (Table 2).

Spatial modeling showed a heterogeneous distribution of elderly mortality from CVDs, both in crude and smoothed rates (Moran's index 0.169815; p=0.02 and Moran's index 0.766288; $\mathrm{p}=0.01$, respectively), with concentration in the eastern region of the state. In the gross rate, when comparing spatial patterns, it was observed that all municipalities with a rate lower than $300 / 100,000$ were displaced to the strata with higher rates. The strata with rates between 401 and 500/100,000 and higher than 600/100,000 showed an increase in the number of municipalities, from 25 to 41 and from 11 to 12, respectively (Figure 2).

The highest crude rates were observed in the municipalities of Água Branca (909.70/100,000), Flexeiras (736.07/100,000) and Passo de Camaragibe (711.91/100,000). After approach to smoothing, the highest rates were observed in Água Branca (658.42/100,000), São Luís do Quitunde (657.09/100,000) and Barra de Santo Antônio (640.11/100,000). The state capital, Maceió, recorded a gross rate of $636.61 / 100,000$ and a smoothed rate of 626.30/100,000 (Figure 2).

In the local Moran's I cluster map, 22 municipalities were located in the Q1 quadrant of the scatter plot, and therefore, considered priorities. Together, these municipalities accounted for $50.3 \%(n=10789)$ of all deaths in the state, with an average gross rate of 587.16/100,000 and an average smoothed rate of 587.19/100,000 (Figure 2).

\section{Discussion}

Despite the reduction in mortality rates from CVDs in recent years, ${ }^{11}$ Brazil is still in a prominent position on the world stage. Part of this is due to socioeconomic, demographic and epidemiological disparities between Brazilian's geographic regions, especially when comparing the north-northeast with the southeast-south axis. ${ }^{3,4}$ 
Table 1 - Sociodemographic characterization of deaths from cerebrovascular diseases among elderly people by sex; Alagoas, Brazil, 2000-2016

\begin{tabular}{|c|c|c|c|c|c|c|}
\hline \multirow[t]{2}{*}{ Variables } & \multicolumn{2}{|c|}{$\begin{array}{c}\text { Male } \\
n=10,797 \\
(50.4 \%)\end{array}$} & \multicolumn{2}{|c|}{$\begin{array}{c}\text { Female } \\
n=10,643 \\
(49.6 \%)\end{array}$} & \multicolumn{2}{|c|}{$\begin{array}{l}\text { Total Deaths } \\
\qquad \begin{array}{c}n=21,440 \\
(100.0 \%)\end{array}\end{array}$} \\
\hline & $\mathbf{n}$ & $\%$ & $\mathbf{n}$ & $\%$ & $\mathbf{n}$ & $\%$ \\
\hline \multicolumn{7}{|l|}{ Age group } \\
\hline $60-69$ & 2,982 & 27.62 & 2383 & 22.39 & 5365 & 25.02 \\
\hline $70-79$ & 3,814 & 35.32 & 3590 & 33.73 & 7403 & 34.53 \\
\hline 80 or over & 4,001 & 37.06 & 4670 & 43.88 & 8670 & 40.45 \\
\hline \multicolumn{7}{|l|}{ Color/race } \\
\hline White & 2,007 & 18.60 & 2235 & 21.00 & 4242 & 19.78 \\
\hline Black & 510 & 4.72 & 437 & 4.11 & 947 & 4.42 \\
\hline Yellow & 22 & 0.20 & 34 & 0.32 & 56 & 0.26 \\
\hline Brown & 4,847 & 44.89 & 4618 & 43.39 & 9465 & 44.15 \\
\hline Indigenous & 7 & 0.06 & 15 & 0.14 & 22 & 0.10 \\
\hline Unknown & 3,404 & 31.53 & 3304 & 31.04 & 6708 & 31.29 \\
\hline \multicolumn{7}{|l|}{ Marital status } \\
\hline Single & 1,386 & 12.84 & 1810 & 17.01 & 3196 & 14.91 \\
\hline Married & 4,407 & 40.82 & 2041 & 19.18 & 6448 & 30.07 \\
\hline Widowed & 1,427 & 13.22 & 3238 & 30.42 & 4665 & 21.76 \\
\hline Divorced & 147 & 1.36 & 111 & 1.04 & 258 & 1.20 \\
\hline Other & 106 & 0.98 & 54 & 0.51 & 160 & 0.75 \\
\hline Unknown & 3,324 & 30.78 & 3389 & 31.84 & 6713 & 31.31 \\
\hline \multicolumn{7}{|l|}{ Schooling } \\
\hline None & 2,644 & 24.49 & 3094 & 29.07 & 5738 & 26.76 \\
\hline 1-3 years & 1,209 & 11.20 & 881 & 8.28 & 2090 & 9.75 \\
\hline 4-7 years & 697 & 6.45 & 569 & 5.34 & 1266 & 5.90 \\
\hline 8-11 years & 260 & 2.41 & 201 & 1.89 & 461 & 2.16 \\
\hline 12 years or more & 93 & 0.86 & 73 & 0.69 & 166 & 0.77 \\
\hline Unknown & 5894 & 54.59 & 5825 & 54.73 & 11719 & 54.66 \\
\hline
\end{tabular}


a) General elderly mortality from CVD

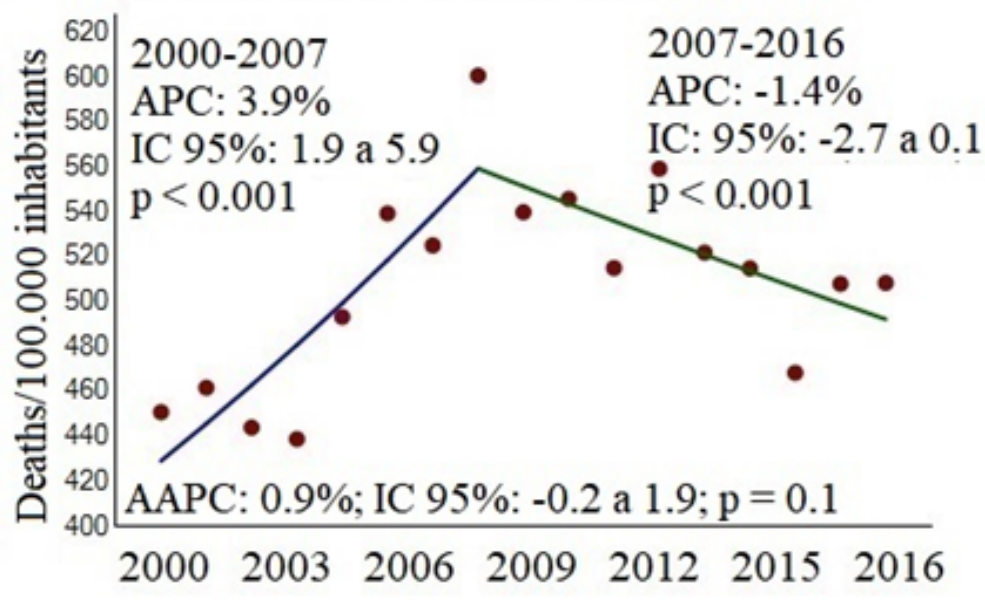

b) Male mortality from CVD

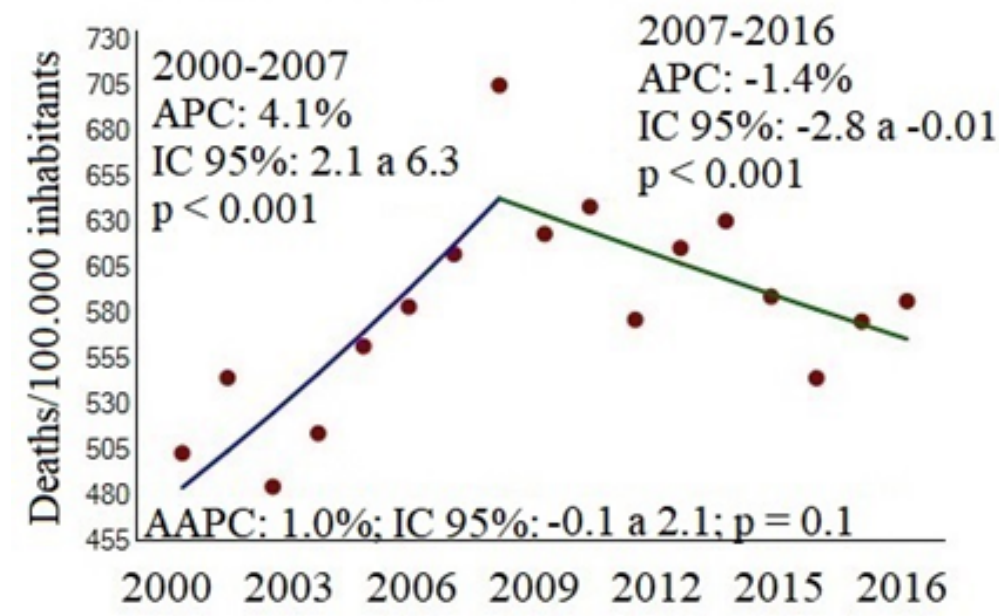

c) Female mortality from CVD

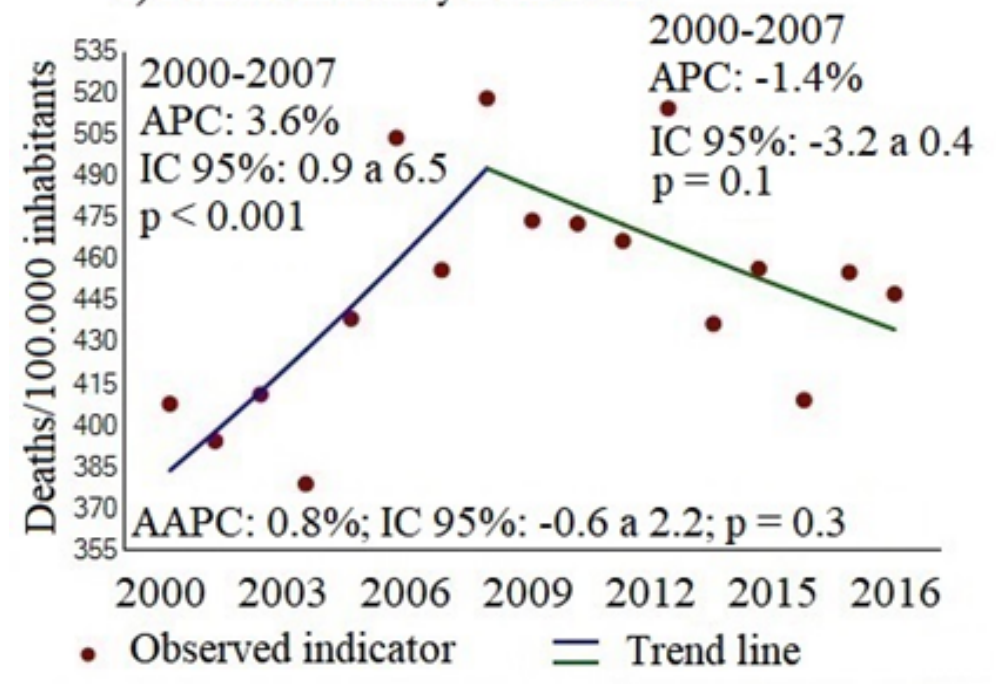

Figure 1 - Time course of the mortality rate from cerebrovascular disease in the elderly population in Alagoas, Brazil, 2000-2016 
Table 2 - Mortality rate in elderly people with cerebrovascular disease, according to sex and categories of the International Classification of Diseases (ICD-10), Alagoas, Brazil, 2000-2016

\begin{tabular}{|c|c|c|c|c|c|c|c|c|c|}
\hline \multirow{2}{*}{ ICD-10 categories } & \multicolumn{3}{|c|}{ Male } & \multicolumn{3}{|c|}{ Female } & \multicolumn{3}{|c|}{ Both sexes } \\
\hline & n & $\%$ & Rate* $^{*}$ & $\mathbf{n}$ & $\%$ & Rate* & $\mathbf{n}$ & $\%$ & Rate $^{*}$ \\
\hline I60 - Subarachnoid hemorrhage & 43 & 31.16 & 2.39 & 95 & 68.84 & 4.12 & 138 & 0.64 & 3.37 \\
\hline I61 - Intracerebral hemorrhage & 698 & 49.89 & 38.93 & 701 & 50.11 & 30.46 & 1399 & 6.53 & 34.17 \\
\hline I62 - Other non-traumatic intracranial hemorrhages & 17 & 44.74 & 0.94 & 21 & 55.26 & 0.91 & 38 & 0.18 & 0.92 \\
\hline I63 - Cerebral infarction & 81 & 60.45 & 4.51 & 53 & 39.55 & 2.30 & 134 & 0.63 & 3.27 \\
\hline I64 - Stroke not specified as hemorrhagic or ischemic & 7502 & 50.32 & 418.44 & 7408 & 49.68 & 321.89 & 14910 & 69.55 & 364.17 \\
\hline I67- Other cerebrovascular disorders & 849 & 47.11 & 47.35 & 953 & 52.89 & 41.41 & 1802 & 8.41 & 44.01 \\
\hline I69- Sequelae of cerebrovascular diseases & 1605 & 53.20 & 89.52 & 1412 & 46.80 & 61.35 & 3017 & 14.07 & 73.69 \\
\hline
\end{tabular}

The mortality profile observed in Alagoas is similar to other states in Brazil. ${ }^{12}$ Age and sex reflected two important processes in demographic dynamics in Brazil: first, population aging and increased life expectancy are accompanied by increased risk of arterial hypertension and atrial fibrillation, key factors in the development of $\mathrm{CVD},{ }^{13}$ second, the feminization of aging, characterized by the predominance of women in the older age groups, especially above 80 years old. ${ }^{1}$ It is estimated that $56.6 \%$ of the elderly population in the state of Alagoas, in 2019, were female. ${ }^{5}$

Among the factors associated with the development of CVDs, social vulnerability has gained a prominent role. Ribeiro et al., ${ }^{1}$ pointed out that low levels of education increase the risk of stroke by 1.2 times in the Brazilian population. Low education can hinder both the search for health services, delaying the accurate diagnosis and initial therapeutic measures, and post-surgical care as well. ${ }^{1}$ These factors directly affect the patient's prognosis and long-term survival. ${ }^{3}$

In addition, we evaluated the influence of marital status on mortality from CVDs in the population of Alagoas. Some authors have reported that marriage appears to be a protective factor against morbidities. ${ }^{16}$ Liu et al., ${ }^{16}$ in a multicenter study involving 12,118 participants, demonstrated that marriage can provide important behavioral, biological and psychosocial resources in the prevention and treatment of related morbidities. In addition, men who live alone are more likely to death, ${ }^{17}$ which is explained, in part, by the greater delay in arriving at specialized services and late initiation of thrombolytic therapy. ${ }^{16}$

Another epidemiological factor was race/color. Lotufo and Bensenor ${ }^{18}$ stated that in Brazil, black individuals have $40 \%$ higher risk for CVDs than white individuals. A study conducted in the state of Bahia showed that $35.0 \%$ of deaths occurred in the brown or black population. ${ }^{19}$ These values differ from those found in the state of Paraná, in which $86.0 \%$ of registered deaths due to CVD occurred in the white race/color population. ${ }^{20}$ However, it is necessary to point out the influence of colonization on the formation of the Brazilian people (African colonization in the case of Bahia and European colonization in Paraná). ${ }^{20}$ Also, the definition of race/ color has a subjective trait, and can be done by prior self-declaration of the deceased, by family members or by third parties, representing a criterion of low agreement. ${ }^{18}$

Although the epidemiological characteristics discussed above have influenced the tendency of a stationary mortality from CVD, other factors must be analyzed. The decreasing mortality trend observed since 2007 may be related to the strengthening of primary care programs in the state of Alagoas, including the consolidation of the Family Health Strategy (FHS), which covered only 14 municipalities in 1994 and expanded to all the 102 municipalities of Alagoas State in 2013. ${ }^{21}$ A report by the National Health Surveillance System of Brazil states the rate of hospitalization for stroke by patients older than 40 years in Alagoas decreased in the period from 2005 to 2007. This corroborates the results found in our study 
(A) Crude mortality rate of elderly people due to CVD, Alagoas, 2000-2016.

Subtitle $[\mathrm{n}=102$ citys $]$

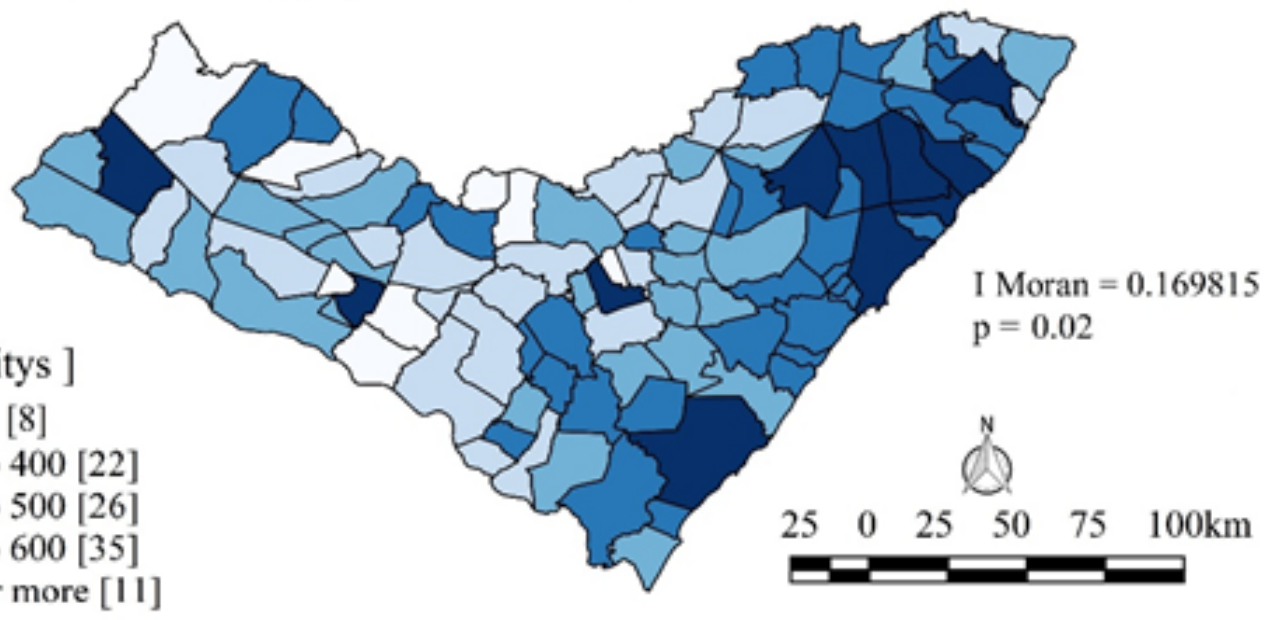

(A) Smoothed mortality rate of elderly people due to CVD, Alagoas, 2000-2016

Subtitle $[\mathrm{n}=102$ citys ]

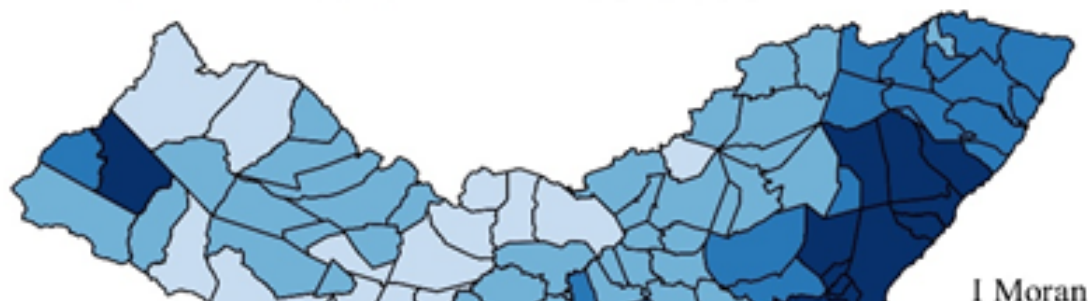

I Moran $=0.766288$

$\square<=300[0]$

301 to $400[18]$

401 to $500[41]$

501 to $600[31]$

600 or more[12]

$\mathrm{p}=0.01$

(A) Moran map of mortality among elderly people with CVD, Alagoas, 2000-2016.

Subtitle

[ $\mathrm{n}=102$ citys ]

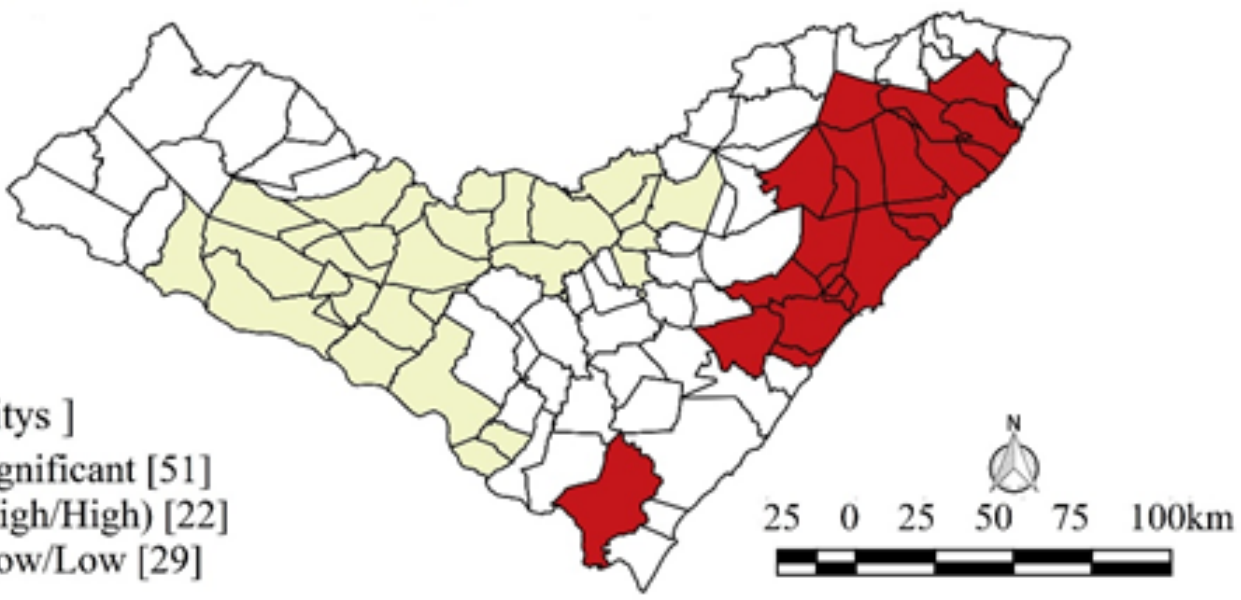

Figure 2 - Spatial distribution of the mortality rate from cerebrovascular disease in the elderly population, Alagoas, Brazil, 2000-2016 
and shows how a well-developed strategy could reduce the number of deaths from CVD in the state..$^{21,22}$

It is also important to mention the heterogeneous spatial distribution of deaths, with the highest concentration in the eastern region of the state. This fact is possibly related to the centralization of specialized health services in the capital Maceió, including the stroke unit of the state general hospital (Hospital Geral do Estado), in operation since $2015 .{ }^{23}$ Such services mainly assist the municipalities located within the first and the second health regions of Alagoas, and the entire first macroregion, equivalent to the eastern territory of the state. ${ }^{24}$ The high concentration of healthcare centers around the capital provides a greater number of diagnosed cases and deaths registered in that region. ${ }^{25}$

This study has some limitations that need to be considered: i) use of secondary data from information systems; ii) it is possible that there was an underreporting of deaths from CVDs in the most interior and least assisted regions of the state, influencing on the spatial distribution of cases found in this study; iii) lack of sociodemographic data of some of the patients, due to error in registration or filling out of the death certificate.

\section{Conclusion}

The study showed that death from CVDs in Alagoas, occurs equally in men and women, and mostly in individuals of mixed race, with low education attainment, and married. There was a downward trend of overall mortality and mortality among men from 2007 onwards. The highest mortality rates were observed in the eastern region of the state.

\section{References}

1. World Health Organization (WHO). Global Health Estimates 2016: Disease burden by Cause, Age, Sex, by Country and by Region, 20002016. Geneva: WHO; 2018.

2. Engelhardt E. Apoplexy, cerebrovascular disease, and stroke: Historical Evolution of terms and definition. Dement Neuropsychol 2017; 11(4):449-53.

3. Lotufo PA, Goulart AC, Passos VMA, Satake FM, Souza MFM, França EB, Ribeiro ALP, Bensenõr IJM. Doença cerebrovascular no Brasil de 1990 a 2015: Global Burden of Disease 2015. Rev Bras Epidemiol 2017; 20(1):129-41.

4. Collaboratos, Gbd 2016 Brazil. Burden of disease in Brazil, 1990-2016: a systematic subnational analysis for the Global Burden of Disease Study 2016. Lancet 2018; 392(1): 760-75.

5. Instituto Brasileiro de Geografia e Estatística (IBGE). Resultado dos Dados Preliminares do Censo - 2010; 2019. Disponível em https://cidades.ibge. gov.br/brasil/al/panorama.
The results of this study can contribute to the development of plans and strategies to reduce CVD deaths and promote healthy aging.

\section{Author Contributions}

Conception and design of the research: Souza CDF, Cunha, EJO, Silva Junior LCF. Acquisition of data: Souza CDF, Cunha, EJO, Silva Junior LCF. Analysis and interpretation of the data: Souza CDF, Duarte ALF, Cunha, EJO, Silva Junior LCF. Statistical analysis: Souza CDF. Obtaining financing: Souza CDF.Writing of the manuscript: Souza CDF, Duarte ALF, Cunha, EJO, Silva Junior LCF. Critical revision of the manuscript for intellectual content: Souza CDF, Cunha, EJO, Silva Junior LCF.

\section{Potential Conflict of Interest}

No potential conflict of interest relevant to this article was reported.

\section{Sources of Funding}

There were no external funding sources for this study.

\section{Study Association}

This study is not associated with any thesis or dissertation work.

\section{Ethics Approval and Consent to Participate}

This article does not contain any studies with human participants or animals performed by any of the authors.

6. Costa MA, Marguti BO. Atlas da vulnerabilidade social nos municípios brasileiros. Brasília: IPEA; 2015.

7. Brasil. Ministério da Saúde. Sistema de informações sobre mortalidade, 2019 Disponível em http://datasus.saude.gov.br/. Acesso em 10 de out, 2019.

8. Kim HJ, Fay MP, Feuer EJ, Midthune DN. Permutation tests for joinpoint regression with applications to cancer rates. Stat Med 2000; 19(3):335-51.

9. Gelman A, Carlin JB, Stern HS, Dunson DB, Vehtari A, Rubin DB. Bayesian Data Analysis: Texts in Statistical Science. $3^{\underline{a}}$ Edição. Crc Press; 2013.

10. Souza WV, Barcellos CC, Brito AM, Carvalho MS, Cruz OG, Albuquerque MFM, Alves KR, Lapa TM. Aplicação de modelo bayesiano empírico na análise espacial da ocorrência de hanseníase. Rev Saude Publica 2001; 35(5):474-80.

11. Nuñez-Gonzales S, Duplat A, Simancas D. Mortalidad por enfermedades cerebrovasculares en Ecuador 2001-2015: Estudio de tendencias, aplicación del modelo de regresión joinpoint. Rev Ecuatoriana de Neurologia 2018; 27(1):16-22. 
12. Bacurau AGM, Ferraz RO, Donalisio MR, Francisco PMSB. Mortalidade por doenças cerebrovasculares em idosos e a vacinação contra a influenza: Estado de São Paulo, Brasil, 1980-2012. Cad Saude Publica 2019; 35(2):117-35

13. Katan M, Luft A. Global Burden of Stroke. Semin Neurol 2018; 38(2):208-11.

14. Cordonnier C, Sprigg N, Sandset EC, Pavlovic A, Sunnerhagen KS, Caso $\mathrm{V}$, Christensen H. Stroke in women - from evidence to inequalities. Nat Rev Neurol 2017; 13(9):521-32.

15. Ribeiro IJS, Cardoso JP, Freire IV, Carvalho MF, Pereira R. Determinants of Stroke in Brazil: A Cross-Sectional Multivariate Approach from the National Health Survey. J Stroke Cerebrovasc Dis 2018; 27(6):1616-23.

16. Liu Q, Wang X, Wang Y, Wang C, Zhao X, Liu L, Li Z, Meng X, Guo L, Wang $Y$. Association between marriage and outcomes in patients with acute ischemic stroke. J Neurol 2018; 265(4):942-48.

17. Ng TP, Jin A, Feng L, Nyunt MSZ, Chow KY, Feng L, Fong NP; Mortality of older persons living alone: Singapore longitudinal ageing studies. BMC Geriatr 2015; 15(126):2-9.

18. Lotufo PA, Bensenor IJM. Raça e Mortalidade Cerebrovascular no Brasil. Rev Saude Publica 2013; 47(6):1201-04

19. Souza-Junior EVS, Jesus MAS, Bezerra CLS, Rosa RS, Boery EN, Boery RNSO. Taxa de mortalidade por infarto cerebral na macrorregião sudeste do Estado da Bahia, Brasil. Revista Eletrônica Enfermaria Actual en Costa Rica. 2018;34

20. Furukawa TS, Mathias TAF, Marcon SS. Mortalidade por doenças cerebrovasculares por residência e local de ocorrência do óbito: Paraná, Brasil, 2007. Cad Saude Publica 2011; 27(2):327-334.

21. Silva MAP, Menezes RCE, Oliveira, MAA, Longo-Silva G, Asakura L. Atenção Básica em Alagoas: expansão da Estratégia Saúde da Família, do Nasf e da componente alimentação/nutrição. Saúde debate 2014; 38(103):720-32.

22. Brasil. Ministério da Saúde. Secretaria de Vigilância em Saúde - Sistema nacional de vigilância em saúde: relatório de situação: Alagoas. $5^{\underline{a}}$ ed. Brasília; 2011.

23. Secretaria de Estado da Saúde - Alagoas. Unidade de AVC do HGE atende mais de 1.100 alagoanos; 2018. Disponível em: http://www.saude.al.gov. br/2018/10/30/unidade-de-avc-do-hge-leva-servicos-especializados-amais-de-1-100-alagoanos/

24. Superintendência de Planejamento e Participação Social - Alagoas. Plano Diretor de Regionalização da Saúde de Alagoas. Maceió: Secretaria de Estado da Saúde; 2011.

25. Albuquerque MV, Viana ALA, Lima LD, Ferreira MP, Fusaro ER, Iozzi FL. Desigualdades regionais na saúde: mudanças observadas no Brasil de 2000 a 2016. Cien Saude Colet 2017; 22(4):1055-1064. 